\title{
Transaction cost perspectives on cooperation: A study of hybrids through foundations
}

lobbying in the $\mathbf{E U}$

Marybel Perez

Center for Philanthropy Studies University of Basel

Published:

Perez, M. Transaction Cost Perspectives on Cooperation: A Study of Hybrids Through Foundations Lobbying in the EU. Voluntas 30, 408-421 (2019)

\begin{abstract}
This article uses a transaction cost economics (TCE) approach to analyze cooperation between nonprofits, governments and firms, namely, hybrids. This is a different concept from hybrids in the nonprofit management literature. In TCE, hybrids are organizational modes of transactions where the parties contribute limited resources, for which they establish modes of coordination. This article explains how the concept of hybrids can be applied to research on nonprofits, illustrating this with an analysis of foundations lobbying in the European Union (EU). As regulatory transactions are organized through hybrids, this article proposes that foundations are likely to participate in EU policymaking for regulatory transactions, which are too costly to solve individually. The results show that foundations participate in different EU regulatory environments; significantly, this includes environments with high coordination costs.
\end{abstract}

\section{Keywords}

European Union, philanthropic foundations, transaction costs 


\section{Introduction}

Increased cooperation among nonprofits is inspiring research on the factors that lead to the formation, transformation, and demise of nonprofits' cooperation with governments and firms (AL-Tabbaa, Leach, and March, 2014; Guo and Acar, 2005; Schiller and Almog-Bar, 2013; Witesman and Heiss, 2016). Past research has identified the characteristics of some forms of nonprofit cooperation, but it is imperative that researchers gain an in-depth understanding of nonprofit cooperation by adopting a comparative perspective that systematically considers nonprofits' alternative modes of cooperation. This article proposes a specific transaction cost economics (TCE) approach that studies cooperation called hybrids. The hybrids TCE approach offers an organizational perspective that models alternatives available for nonprofits to cooperate, as well as the mode of cooperation most suitable for their purposes.

Before continuing, it should be noted that the nonprofit management literature also studies hybrids; however, its emphasis is not on the transaction. Hybrids in nonprofit management refer to organizations combining market and public logics: earning revenue and creating social value (e.g., Jäger \& Schröer, 2014). In other words, hybrids constitute a type of nonprofit (e.g., Battilana \& Lee, 2014; Brandsen, de Donk, \& Putters, 2005; Jäger \& Schröer, 2014). Analytically, hybrids have been introduced into nonprofit management to account for wider classifications of nonprofits (Brandsen, de Donk, \& Putters, 2005) to understand the trend toward "marketization”, for example (Jäger \& Schröer, 2014).

In TCE, hybrids are modes of organization for transactions of intermediate asset specificity that are not efficiently organized through hierarchies or markets (see Section 1). Hybrid modes of organization are "forms that involve multiple partners pooling some strategic decision rights, and even some property rights, while keeping distinct ownership over key 
assets, so that they require specific governance to monitor and discipline their interactions" (Ménard, 2010: 176). As a result, TCE hybrids have been introduced to account for a larger number of alternative structures of production (Williamson, 1991). In other words, TCE assumes that organizations — whether governments, nonprofits, or firms — pursue their transactions through a mix of markets (e.g., the procurement of computers), hierarchies (e.g., hiring specialized labor), and hybrids (e.g., cooperating to organize the delivery of a good or service).

By studying hybrids, TCE contributes to the analysis of an increasing number of transactions organized through cooperation between firms and between firms and governments (e.g., Ménard, 2004; Jolink \& Niesten, 2012). Hybrids have been useful in understanding new forms of adaptation to uncertainty and explaining when and how cooperation constitutes a comparative advantage for organizations. As a result, franchise, subcontracting, supply chain, and joint venture studies, among others, have considerably benefited from this approach.

To the best of my knowledge, TCE accounts of nonprofits have not considered hybrids as one of the alternative modes that nonprofits can use to structure their transactions (a few have done it indirectly such as Kumar \& Malegeant, 2006; Leat, 2016; Oster, 1992, 1996; Young, 1989; Young \& Faulk, 2010). Consequently, the overall purpose of this article is to explain how hybrids provide explanatory power to analyze nonprofits' adaptability to collective action problems.

To this end, I examine the case of foundations lobbying in the European Union (EU). Through lobbying, several types of interest groups contribute to elaborating policies and providing specific information and skills. Consequently, I argue that lobbying is a mechanism that foundations use to organize regulatory transactions. Regulatory transactions tackle 
asymmetries that arise from collective action through cooperative arrangements. As I explain later, regulatory transactions belong to what Commons (1950) defines as rationing, one of the three fundamental TCE transactions. Rationing takes place between different organizations, such as supply chains, joint ventures, and policymaking; it can also take place between stakeholders in an organization, such as when a firm's board members define compensation schemes or budgets.

Although many studies have examined the influence of foundations in politics (e.g., Ball, 2008, 2012; Ferris, 2009; Kretchmar, Sondel, \& Ferrare, 2014; Mandeville, 2007; Roelofs, 2003; Stone, 2010), their direct participation in lobbying, as part of the interest group collective, has been largely neglected. This is partly the result of US barriers to foundation lobbying $^{\mathrm{a}}$ (see Mandeville, 2007; although this may change with a revision of the Johnson Amendment ${ }^{\mathrm{b}}$ ), barriers that do not exist in the EU. Therefore, the EU constitutes a unique case with which to examine this question.

Anheier and Daly (2007: 71) found that European foundations have only a marginal interest in EU politics and constitute the "latecomers" on the EU scene. In fact, the EU Transparency Register (TR, 2017), a comprehensive official database providing information on individuals and entities lobbying in the EU, reveals that the number of foundations has been increasing steadily since 2008 (Graph 1) (registered organizations must update their data every year; therefore, inactive organizations tend to disappear). This trend raises a question seldom asked by researchers: "What compels foundations to lobby?" I argue that foundations participate in EU policymaking for regulatory transactions that are too costly to solve inside the organization. 
Graph 1. Number of foundations registered in the EU Transparency Register per year.

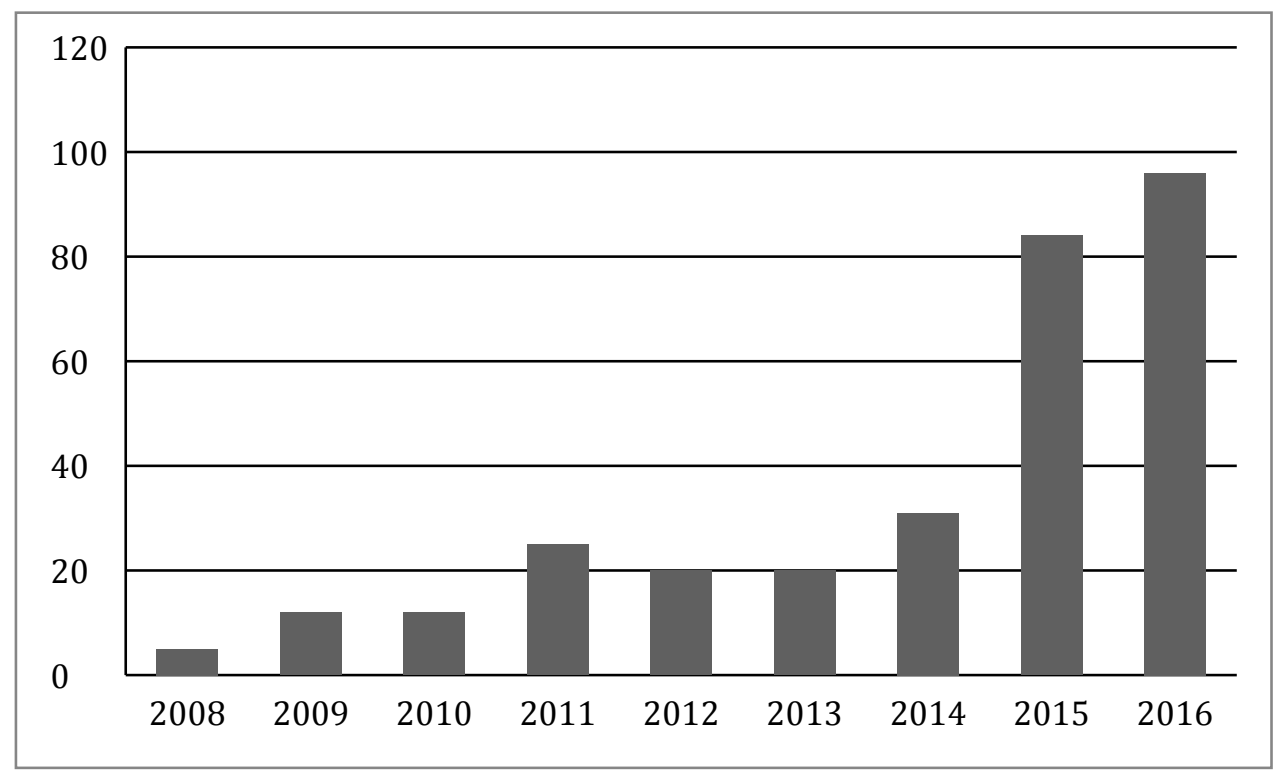

Source: Adapted from the EU Transparency Register (2017). 
The argument proceeds in three parts. Focusing on the case of foundations and emphasizing hybrids, the first point explains the three main elements of TCE: defining the type of transaction, the alternative modes of organization for transactions, and the efficient alignment principle. The second point explains regulatory transactions as hybrids and derives propositions to explain foundations lobbying in the EU based on Wilson's $(1974,1989)$ model of policy environments. The third point explains EU lobbying as a hybrid mode of organization. Although EU lobbying is frequently described as a market arrangement for procuring transactions, I argue that EU lobbying lacks the characteristics of autonomous adaptation and the negligible control arrangements of markets. For the remainder of the paper, in the fourth section, the foundations registered in the TR are analyzed in light of the propositions derived in the model presented in the second section. The fifth section concludes the discussion, highlights this article's key findings, and offers recommendations for future research.

\section{Transaction costs through the lens of foundations}

Transaction costs are the costs of "planning, adapting and monitoring" a transaction (Williamson, 1985: 20). These costs include ex ante costs, which are the costs of "drafting, negotiating and safeguarding an agreement," and ex post costs, which appear when the completion of a task diverges from what the agreement stipulated (Williamson, 1985: 20). Both types of costs are interdependent and need to be defined a priori.

\subsection{Type of transactions}

The costs of transactions vary according to three dimensions: asset specificity, uncertainty, and frequency (Williamson, 1985, 1999). Asset specificity refers to the degree to which the assets for a transaction can be easily assigned to other transactions without losing value; therefore, the less likely the assets are to be relocated, the more specific and costly they are. 
Uncertainty is the extent to which the implicated parties' bounded rationality (time and cognitive limitations for processing information) and opportunism (deceitful behavior) affect the completion of a transaction; therefore, when asset specificity increases, the likelihood of uncertainty increases and mechanisms of control are needed, adding costs to the transaction. Finally, frequency stipulates that the more costly the transaction is due to asset specificity and uncertainty, the longer the relationship between parties will tend to last. Accordingly, the costs of transactions will rise as the costs of all three dimensions increase, and the transaction will be described as idiosyncratic (Figure 1a).

To illustrate, imagine two types of transactions: one with low costs and one with high costs. In the first, a foundation with the general mission to improve education deploys a program to buy computers. The funding for computers can easily be redeployed (to buy books instead), and the implicated parties (computer providers and the foundation) can assess the outcome (the quality and number of computers purchased). The relationship between the parties ends once the computers are delivered and paid for.

In the second, a foundation with the specific purpose of saving an endangered species will bear high asset and uncertainty costs because the land used by the species cannot be redeployed and because the care of the species requires distinct environmental and veterinary knowledge. The veterinary care may be an idiosyncratic transaction. In contrast to land cleaners who do not require specialist knowledge, a veterinarian needs specialized knowledge to conserve the endangered species. While the foundation hires land cleaners in spot markets, specialized veterinarians are difficult to find in spot markets (see Williamson, Wachter, \& Harris, 1975 for more on job idiosyncrasy and spot and structured labor markets). In other words, alternative sources to find specialized veterinarians are considerably limited compared to land cleaners or veterinarians for domestic animals. Accordingly, it is hard to sell the 
veterinarian's specialization in spot markets, where veterinarians for domestic animals rather than for endangered species are most valued, without losing productive value. Moreover, ex post costs occur because the veterinarian will specialize in the treatment of the species in question, which may not be marketable without losing productive value (see Williamson, Wachter, \& Harris, 1975; Williamson, 1985: 240 on task idiosyncrasy). Meanwhile, the foundation will invest in the veterinarian's skill development, which is hardly redeployable should the veterinarian leave the foundation. This ex post status shows a "small numbers bargaining situation" (Williamson, Wachter, \& Harris 1975: 256; Arrow, 1969) where, due to the specific knowledge acquired, the veterinarian is in an advantageous position vis-à-vis competitors to adapt to unforeseeable changes; he or she may be tempted to act opportunistically. In sum, the relationship between the veterinarian and the foundation bears sizeable transaction costs due to the veterinarian's knowledge advantage vis-à-vis the foundation (bounded rationality), his or her advantage vis-à-vis competitors due to his or her specific knowledge (small numbers), the possibility that he or she uses the advantage to act opportunistically, and the need to frequently adapt to unforeseen circumstances that may affect the endangered species (uncertainty). Consequently, when the foundation's need for veterinary care is significant due to knowledge specificity, the high uncertainty regarding the wellbeing of the species, and the high frequency of demand of services, the relationship will tend to be organized in a hierarchical manner (Figure $1 \mathrm{~b}$ ).

A note of caution should be included. Opportunism may operate differently in nonprofits than it does in for-profits. Following Valentinov (2008a, 2008b), the alignment of the intrinsic motivation of the veterinarian with the foundation mission - both have an intrinsic interest in conserving endangered species - may weaken his or her willingness to act opportunistically. According to Valentinov, a mechanism that nonprofits use to control their employees' opportunistic behavior and to ensure motivation alignment is setting lower wages (2008b). 
This may be the case for endangered species veterinarians (e.g., James, 2016). The US Bureau of Labor Statistics pointed out that despite the increasing demand and significant requirements of specialization, endangered species veterinarians earn lower salaries than veterinarians for domestic animals because they work for governments, research institutions, or nonprofits rather than private practices (2017).

\subsection{Alternative modes of organization}

Adaptation is an essential factor when assessing the suitability of different modes of organization for different types of transactions (Williamson, 1991). Adaptation refers to the incentives the mode of organization provides to adjust to any changes that appear during the transaction (i.e., the incentives to adjust to ex post costs). Markets are considered high incentive structures because the price system provides the necessary motivations for parties to adjust autonomously to changes without the need for costly control arrangements.

However, as transaction costs increase, the relationship between buyers and suppliers becomes interdependent; thus, the parties' utility maximization becomes dependent on one another. One party's asset investments are affected by another party's asset investments, and vice versa. In these cases, adaptation does not take place autonomously through price systems, but through increasingly complex and frequent bargaining for every change. Bargaining for every change can add costs to the point where the costs exceed the benefits of the transaction. To reduce the added costs of frequent bargaining, the parties may estimate advantageously to create strong control arrangements, which are easy to adjust. This is how hierarchies economize on transaction costs (Williamson, 1985). Hierarchies correspond to cases where strong control arrangements (the use of authority) are deemed less costly than frequent bargaining to accomplish transactions. 
Consequently, hierarchies are on the right end when defining modes of organization as a continuum because of the low incentive structures for autonomous adaptation and strong control arrangements (Figure 1b). Markets are on the left end because of high incentive structures for autonomous adaptation with negligible control arrangement. Meanwhile, hybrids are in the middle because they entail intermediate incentive structures and control arrangements (Williamson, 1979, 1985, 1991).

Hybrids are organizational modes where the parties contribute limited assets, for which they establish modes of coordination. This requires the parties to "maintain distinct property rights and remain independent residual claimants" for all but any shared assets (Ménard, 2004: 351). As with hierarchies, the decision to organize a transaction through a hybrid mode depends on the difficulty of predicting ex post costs and the risk of uncertainty, but what is crucial for hybrids is identifying the opportunity to seize positive externalities. Ménard (2013) argued that cost minimization is an insufficient justification for the parties to decide to organize a transaction through coordination. Crucially, it is the identification of added value, such as increased scale and scope, complementarity, and learning effects, that moves the parties to engage in hybrids. As a result, identifying "mutual dependence as a source of value" (Ménard, 2010: 179) drives the parties to share both the risks and the returns (Ménard, 2004).

A specific structural setting is necessary to coordinate the distribution of returns and risks due to the collective character of hybrids. Hybrids rely on a coordinating entity to which the parties cede property rights, decision rights, and the distribution of benefits from the shared assets. Therefore, in contrast to hierarchies and markets, where adaptation is effected autonomously or through authority, the adaptation of hybrids is effected through coordination, which is frequently embodied by a "strategic center" (Ménard, 2010: 178). Nevertheless, the efficacy of the coordinating entity depends on the cooperation of the parties; therefore, when 
parties refuse to cooperate, hybrids may refer to external authorities, such as courts, to enforce the entity's resolutions. Moreover, facilitating coordination depends on the existence of information systems that reduce uncertainty, such as joint datasets (Ménard, 2013: 1091).

\subsection{Efficient alignments}

Comparing all three modes of organization, markets have the lowest transaction costs; nevertheless, the efficiency of each mode of organization must be defined in relation to the costs of the transaction. This observation is the economizing principle—or efficient alignment hypothesis(see Williamson, 1991: 278 on sub-optimal alignment)—on which TCE rests (Williamson, 1985) (Figure 1c).

This principle requires an examination of how foundations determine whether the costs of engaging in policymaking are compensated by the anticipated returns. Returning to the examples presented above, I now consider whether the transactions between the first foundation and the computer suppliers, and the second foundation and the veterinarian, are best carried out through markets, hybrids, or hierarchies.

The transaction between the first foundation and the computer suppliers is a standard transaction where the identity of the suppliers is irrelevant as long as they provide the standard computers required. No critical changes during the transaction are expected because it is possible to assess ex ante and ex post costs; consequently, control arrangements are unnecessary. Accordingly, the most efficient mode to organize the transaction is the market, where the foundation determines the characteristics and number of computers required, asks for estimates from different suppliers, and buys from the supplier that presents the best quality-price relation. 
As explained above, the transaction between the second foundation and the veterinarian is idiosyncratic. If the foundation decides to adopt the cheapest mode of governance — markets — it must (re)negotiate contracts every time an essential change takes place, such as members of the species reproducing, getting ill, or dying. This mode of organization is thus highly inefficient, since the species' well being must be placed on hold while new contracts are negotiated. A more efficient solution would be a hierarchical transaction where the foundation develops a monitoring system that determines when the veterinarian is not acting in the foundation's best interests so it can apply corrective measures (e.g., Cheung, 1983; Coase, 1937; Williamson, 1985: 206 and 240). It is true that developing the monitoring system is costly, but it ensures that the transaction runs smoothly despite any changes; therefore, the returns compensate the transaction costs.

Consider a third case. For the second foundation, successfully accomplishing its mission depends on habitat management, particularly, banning invasive alien species (IAS) introduced by humans. The foundation has several options to discourage and control the effect of IAS. First, it may contract with a firm to develop IAS rules and control mechanisms. The ex ante costs involve finding the right partner of trade in a spot market, and the ex post costs involve devising forms to assess and monitor IAS rules and control mechanisms. Second, the foundation may internally develop IAS rules and control mechanisms. In this case, the ex ante costs involve elaborating, adopting, and enforcing rules to control the introduction of IAS, for which it needs specific knowledge that the board may lack. Here, the ex post cost is generated from devising a form to monitor the performance of IAS rules and control mechanisms.

In order to identify the most efficient mode to organize the control of IAS introduction, we must consider that this is a transaction with high frequency (an offense can take place at any 
time) and a degree of bounded rationality (rule effectiveness cannot be fully assessed ex ante, and monitoring is necessary). Therefore, the first alternative may be less efficient.

However, the third alternative would be more efficient than the second. Here, the foundation partners with agents concerned with controlling the introduction of IAS. In other words, the most efficient mode of organization would be to pool resources (Ostrom, 1990, 2010) with actors who have the specific expertise and capacity, such as interest groups, politicians, and civil servants, to create rules and control arrangements.

Foundations can use different types of partnerships to pursue this goal (e.g., Young \& Faulk, 2010). Continuing with the IAS regulation example, I focus on their participation in policymaking. Regulating IAS will help the foundation to reduce the cost of rule elaboration and monitoring by including nonprofits, legal advisors, authorities, and policy experts with specific knowledge on IAS who will, for instance, expand the scope of scenarios and cases of the offenses covered. As a result, the foundation is better protected from uncertainty. A cooperative approach to IAS regulation will reduce monitoring and control costs by creating a comprehensive mode of control by which specific authorities are assigned the duty of implementation (ministries, local governments, police, and courts). Finally, as expected in a hybrid mode of organization, the foundation and the partners may identify added value. Larger deterrent effects on offenders and increased scope of action, which will help to achieve the goals more efficiently, are two examples of added value. These were some of the arguments used to develop EU legislation no. 1143/2014 on IAS (Genovesi \& Shine, 2004; Kettunen et al., 2008; Stokes et al., 2006). One of the members of the working group on this EU regulation ${ }^{c}$ was the European Centre for Nature Conservation (ECNC), a foundation with headquarters in the Netherlands which is part of the empirical study. 


\section{Regulatory transactions as hybrid modes of organization}

As firms and nonprofits, public agency transactions can be organized through alternative modes (Moe, 1995, 2007; Williamson, 1999; Wilson, 1989) (Graph 2). For example, government computer supply may be best carried out through markets, as was the case for the foundation above (for more about procurement transactions, see Williamson, 1999; Wilson, 1989: 121). Meanwhile, transactions that require authority and command, such as foreign affairs and the military, may be best conducted through hierarchies (for more on sovereign transactions, see Williamson, 1999; Wilson, 1989: 359).

This study concerns transactions of a third kind: regulatory transactions (Graph 2). These transactions reduce uncertainty by addressing asymmetries (e.g., endangered species-invasive species, employees-employers, etc.) with specific assets (Williamson, 1999; Wilson, 1989). Regulatory transactions tackle asymmetries rising from collective action (Commons, 1950); these transactions are not exclusive to public agency — for example, boards of firms and cooperative assemblies also deal with regulatory transactions (Commons, 1950: 56). Regulatory transactions adopt hybrid modes of organization because they regulate collective action. Interest groups, politicians, and civil servants contribute expertise and capital to creating a coordinating entity (e.g., policies, agencies, courts, etc.). ${ }^{\mathrm{d}}$ It is important to understand the mention that it has been argued that Commons' rationing transactions - to which, I proposed in the introduction, regulatory transactions belong - are suitable for understanding nonprofits because, by highlighting common interests between parties, the transactions consider the public good character of nonprofits, an aspect allegedly neglected by the new institutionalism on which most of this article is rooted (Valentinov, 2009, 2012). As it is observed in this article, this proposition is worth being empirically tested because not all the regulatory transactions nonprofits participate in are characterized in terms proposed by 
institutionalists - see below, for instance, the interest group environment and the entrepreneurial environment (also Moe, 2011).

Wilson (1974) explained that the causes and organization of regulatory transactions in public agency depend on how the perceived costs and benefits of the regulation are distributed. Uncertainty about costs and benefits increases interest group activity; moreover, the distribution of costs and benefits creates policy environments (i.e., modes of organization where interest groups act distinctively) (Wilson, 1989: 72) (Figure 2).

In the clientelist environment, interest groups belong to a specific community, such as an industry, and are interested in regulation as a means of improving comparative advantage. This kind of regulation requires knowledge that the industry will share with government authorities in order to find satisfactory solutions. In the interest group environment, the groups represent different communities with competing intentions, resulting in winners and losers. The variety of groups is useful for civil servants and politicians to build their legitimacy; therefore, this environment is highly politicized (Williamson, 1999; Wilson, 1989). In the entrepreneurial environment, the groups bearing the costs belong to a specific community, such as an industry, but in contrast with the clientelist environment, they resist regulation. As most of this regulation is the result of "attacks" on public interest, politicians adopt an entrepreneurial attitude (Wilson, 1989: 80). In majoritarian environments, neither the beneficiaries nor those who bear the cost of regulation can be identified as groups or organized. An example of majoritarian environments is the one that led to EU legislation no. $1143 / 2014$ on IAS; here, the beneficiaries are all of the species that the regulation protects from harm by IAS. The costs are borne by agents categorized as "offenders" and by the public agencies enforcing the law. 
Figure 1. Three aspects of transaction costs

(a)

Cost of transaction

(c)

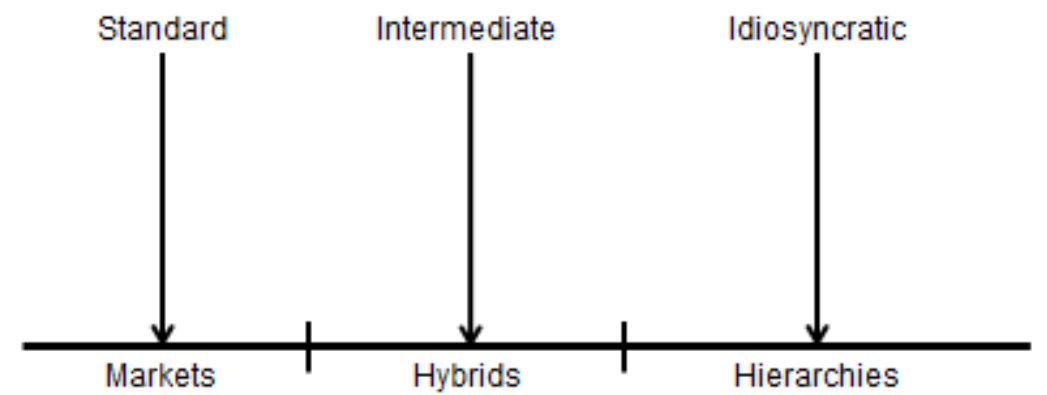

Source: Own elaboration 
Following Williamson (1991: 284), the transaction costs of these regulations can be estimated as public agency costs of governance and asset specificity (Graph 2). As a result, entrepreneurial environments are closer to markets, whereas majority environments are closer to hierarchies. However, Wilson argued that interest groups increase their activity when they perceive "threats" to their costs and benefits (1974: 136). Accordingly, if certain threats to costs and benefits increase interest group activity more than uncertain threats, then it is expected that the curve of interest group participation would decrease proportionally to public agency transaction costs (Graph 2). This proposition is examined further in the empirical analysis below. Nevertheless, the ECNC's participation in IAS legislation suggests that foundations are not only driven by threats, but also by opportunities to increase benefits (again, added value is an important driver for hybrids). In fact, Wilson (1989: 83) suggested that nonprofits, particularly foundations, have played an important role in representing dispersed interests in majoritarian environments; therefore, nonprofits may follow a different logic from other interest groups. 
Graph 2. Public agency transactions and modes of organization

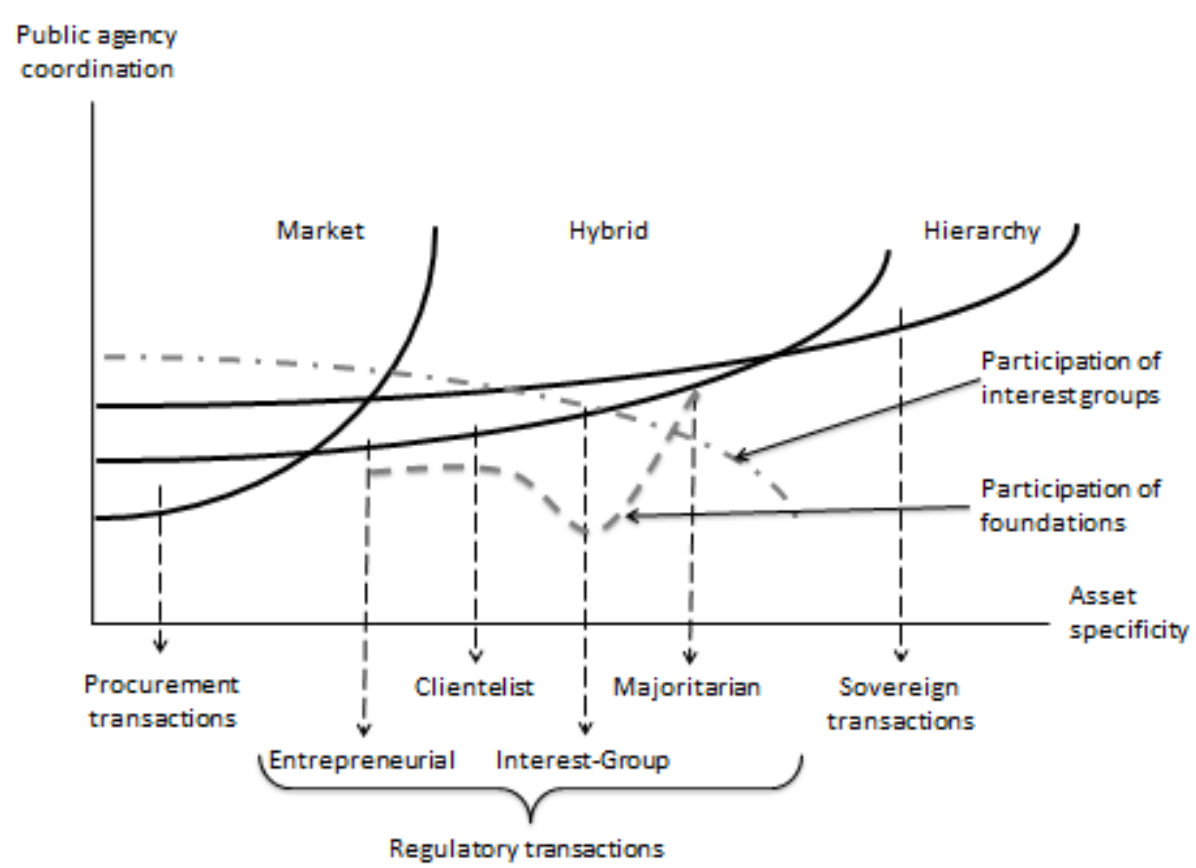

Source: Adapted from Williamson (1991) and Wilson (1974, 1989) 


\section{EU lobbying as a hybrid mode of organization}

Notwithstanding this explanation of regulatory transactions as intermediate transactions, scholars frequently define lobbying as a market mode of organization where interest groups provide expertise in exchange for influence (Lowery, 2007; Lowery \& Gray, 2004). A suboptimal alignment may result if lobbying processes are a market mode of organization and the policies in question are idiosyncratic. Markets are characterized by high incentive structures with negligible control arrangements, while lobbying in the EU is increasingly organized through intermediate incentive structures and control arrangements, which are determined by the idiosyncrasy of the transactions.

First, the role of nonprofits as legitimate partners in regulatory transactions has been increasingly recognized and institutionalized since the legitimacy crisis in the 1990s (EC, 2001), which led to initiatives to transform EU governance in the 2000s (European Commission [EC], 2002). Nonprofits' participation in policymaking is now codified in the Treaty of the EU and the Treaty of the Functioning of the EU. The EU justifies, for instance, financial support as an incentive to improve nonprofit capacity to strengthen civil society, improve governance, and develop policy (EC, 2015). Research shows that the number of interest groups in the EU, particularly nonprofits, is increasing (Greenwood \& Dreger, 2013).

Second, incentive and dissuasion mechanisms have been implemented to control access. For instance, the EU Transparency Register (TR) is a database run by the TR Joint Secretariat (TRJS). Here, organizations and individuals seeking to access consultation processes voluntarily record operational information and information related to their activities in the EU (participation in EC groups, accreditation to the European Parliament [EP], etc.). The EC and the EP launched the TR in $2011^{\mathrm{e}}$ with the intention of improving transparency and 
accountability in policymaking. The EP has announced its aspiration to make it mandatory (EP, 2015).

Although registration in the TR is voluntary, studies indicate that registration amounts to de facto accreditation (Broscheid \& Coen, 2007; Greenwood \& Halpin, 2007). After the EU improved the technical aspects and the system of incentives in January 2015, registration increased, and it is probable that the large number of foundations registered from 2015 onward is due to this change (Graph 1). The new incentives include patronage by the EC and EP, facilitated access to EP members and staff, participation as speakers in EP committee hearings, authorization to organize or co-host events at the EP, and the facilitated transmission of information by both institutions.

Third, processes of consultation (lobbying) have established rules of conduct. A set of principles and standards for consultation processes the EC developed has been in force since 2003 (EC, 2002). These principles and standards establish equal treatment and inclusiveness as the main guiding principles for participation; further, openness, accountability, effectiveness, and publicity are the main guiding principles for the processes. The principles and standards also assign the responsibility for applying these principles to both parties involved: the EC and the interest groups. In parallel with this document, the EC developed the transparency portal, a website allowing users to access information on consultation processes.

The EU's forms of consultation (lobby arenas) vary between open access and focused access. Open access consists of public consultations that are accessible online to organizations and individuals. Focused access is organized when the EU requires specific expert information. High-level groups, consultative committees, expert groups, and intergroups are examples of EU consultations with focused access. Focused consultations have established standards for 
consultation, operation, and information use (e.g., EC, 2010). The EC has a register of "Expert Groups and Other Similar Entities" that features lists of formal groups organized by the EC and informal groups organized by EC departments and other offices. Similarly, the EP has enforced rules on the organization and operation of intergroups since 1999 (EP, 1999). Unfortunately, the TR's data are incomplete and do not allow for examination of a relation between these different types of organizations and hybrids in the empirical analysis.

\section{Foundations participating in EU consultation processes}

In this section, I analyze EU TR data on foundations with the aim of assessing how threats to costs and benefits determine patterns of foundation participation in EU regulatory environments. To this end, a number of variables that reflect foundations investments in participation in EU lobbying are used.

\subsection{Data}

By the end of 2016, there were 11,081 individuals and entities registered in the TR. Section III of the TR corresponds to non-governmental organizations (NGOs), which is the global label given to foundations and associations among other nonprofits. In 2016, there were 2,793 organizations registered as NGOs (25\% of the total number of entries in the TR). Among these, there were 306 (11\% of the NGOs). These foundations correspond to organizations reporting that they are legally registered as foundations and those self-identified as foundations.

In the TR, foundations have to register organizational information (e.g., mission, legal status, address) and EU activity information (e.g., participation in high-level groups and intergroups, number of staff involved in EU activities, etc.). For the purposes of this analysis, the following items provided relevant and valid information: EU initiatives followed, 
participation in high-level groups and intergroups, number of full time equivalent (FTE) staff involved in EU activities, number of staff accredited to the EP, estimated costs of participating in EU activities (absolute and range), and financial return.

The statistical analysis was limited because foundations do not extensively report on the EU initiatives they follow, their participation in high-level groups, or their participation in intergroups. Therefore, only 66 foundations were included in the analysis of regulatory environments. The regulatory environment (Figure 2), followed by each foundation and the policy type, were classified after examining EU initiatives followed, participation in highlevel groups, and participation in intergroups. Policy topics were classified according to the division of competences within the EU.g To ensure classification reliability, a second researcher conducted a blind classification.

The variable regulatory environment had four values: $0=$ clientelist, $1=$ interest group, $2=$ entrepreneurial, and $3=$ majoritarian. The variable policy type followed a scale from 0-23. Because the number of foundations reporting absolute estimated costs was limited, the estimated costs as a range, which all foundations reported, were included in the analysis. The estimated costs as a range were converted to a scale using the end value of each range. Absolute numbers were used for EP staff accredited, FTE, staff involved, estimated costs (absolute and range), and revenue.

Non-parametric tests where applied in the statistical analysis because the sample is nonnormally distributed. A Fisher's exact test was conducted for the statistical analysis between policy types and policy environments because $98.5 \%$ of the cells had an expected count of less than five. A Kruskal-Wallis test was used to analyze between environments and the 
remaining variables because the former is a categorical variable with four values and the latter is continuous.

\subsection{Descriptive statistics}

The characteristics of foundation lobbying in the EU are somewhat different than those of European foundations located globally. The majority of foundations lobbying in the EU have head offices in the Netherlands, Belgium, and Poland; they host half of the foundations that are registered in the TR (Table 1). Regarding the distribution of foundations in Europe, Germany has the largest number (roughly 19,150), followed by Poland, Spain, Sweden, Switzerland, the UK, and the Netherlands (Fondation de France \& CerPhi, 2015). 
Table I. 306 foundations by country

\section{Number of}

\section{foundations per}

\section{Head office's country}

country

Argentina, Bosnia-herzegovina, Canada, Hong

Kong, Israel, Kyrgyztan, Lituania,

Luxembourg, Macedonia, Moldova,

Philippines, Singapore, Slovakia, Ukraine

Albania, Denmark, Finland, Hungary, Latvia,

Malta, Slovenia

Austria, Bulgaria, Estonia, Ireland

Greece, Norway

Sweden

France, Romania

6

Italy, Spain 10

United States 15

Switzerland 17

Germany, United Kingdom 20

Poland 23

Belgium 30

Netherlands 96

Total 306

Source: Elaborated with data from the EU Transparency Register (2017). 
The total revenue that the 306 foundations reported amounts to 6.17 billion Euros, and the median revenue is 0.54 million Euros (Table 2). This amount is far from the average endowment of foundations in Western Europe, which amounts to between 3.5 and 4.5 million Euros (FF \& CerPhi, 2015).

The 66 foundations included in the sample do not significantly differ from the 306 foundations registered in the TR. Foundations both at the population and sample levels focus significantly on 4 of the 23 EU policy topics: environment, health, freedom, security and justice, and internal market (Graph 3). 
Graph 3. Number of foundations by EU policy topic

Social policy

Research and innovation

Regional policy

Maritime affairs and fisheries

Internal market

Industry

Health

Freedom, security and justice

Fraud prevention

Foreign and security policy

EU citizenship

Environment

Enlargement

Energy

Education, training and youth

Economic and monetary affairs

Development and Cooperation

Culture

Conservation of marine biological resources

Commercial

Civil Protection

Agriculture

Administrative cooperation
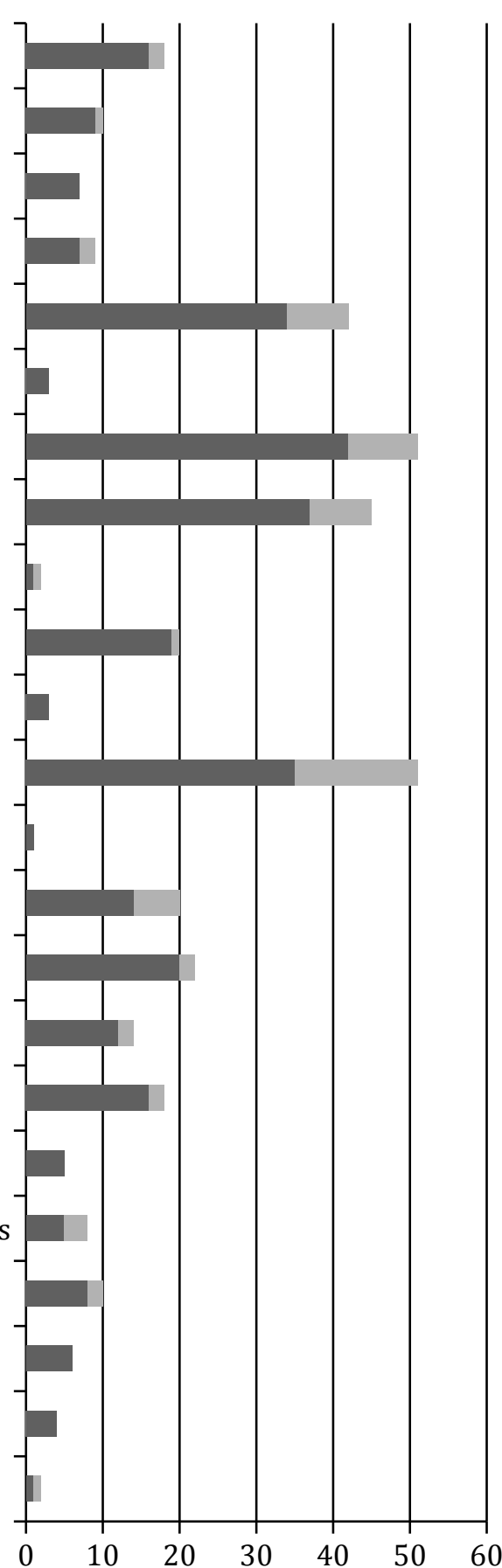

306 foundations $\quad 66$ foundations

Source: Adapted from the EU Transparency Register (2017). 
The FTE staff numbers are similar for both the foundation population and for the sample with one FTE staff (Table 2). The numbers change slightly for EP-accredited staff ( $M d=$ two EPaccredited staff for the population and three for the sample). The total revenue of the sample accounts for $26 \%$ of the population; therefore, their median return is higher. The median estimated costs (as absolute amounts) are higher for the sample than for the population (52,000 Euros and 39,865 Euros, respectively). The estimated costs as a range start at 0-9,999 and end at $>10,000,000$. For both the population and the sample (145 and 30 foundations, respectively), the majority of the foundations report costs in the range of 0-9999. 
Table II. Comparative values of variables

\begin{tabular}{|c|c|c|c|c|c|}
\hline \multirow{3}{*}{ Foundations } & \multicolumn{5}{|c|}{ Estimated costs } \\
\hline & & FTE & (absolute & EP accredited & \\
\hline & & & amount) & staff & Revenue \\
\hline \multirow{6}{*}{$\begin{array}{l}\text { Population } \\
\text { (306) }\end{array}$} & $M d$ & 1.25 & 39865 Euros & 2 & 541849 Euros \\
\hline & & & 21.66 million & & 6176.19 \\
\hline & $s$ & 1798.75 & & 185 & \\
\hline & & & Euros & & million Euros \\
\hline & $n$ & 306 & 70 & 63 & 283 \\
\hline & $\%$ from population & 100 & 23 & 21 & 92 \\
\hline \multirow{6}{*}{ Sample (66) } & $M d$ & 1 & 52000 Euros & 3 & 871018 Euros \\
\hline & & & & & 1593.47 \\
\hline & $s$ & 246.75 & 728203 Euros & 73 & \\
\hline & & & & & million Euros \\
\hline & $n$ & 66 & 12 & 20 & 63 \\
\hline & $\%$ from population & 22 & 4 & 7 & 21 \\
\hline
\end{tabular}

Source: Elaborated with data from the EU Transparency Register (2017). 


\subsection{Results}

Foundations' participation in regulatory transactions does not follow the predicted curve for interest groups (Graph 2). The foundations analyzed here participate in entrepreneurial and clientelist environments to a similar degree (17 foundations in each), and they participate significantly more than in interest group environments (7 foundations) (Figure 2). Importantly, foundations significantly participate in majoritarian environments. Figure 2 gives some examples of the EU initiatives followed by the foundations in each regulatory environment. 
Figure 2. Some EU initiatives followed by 66 foundations, by regulatory environment (number of foundations)

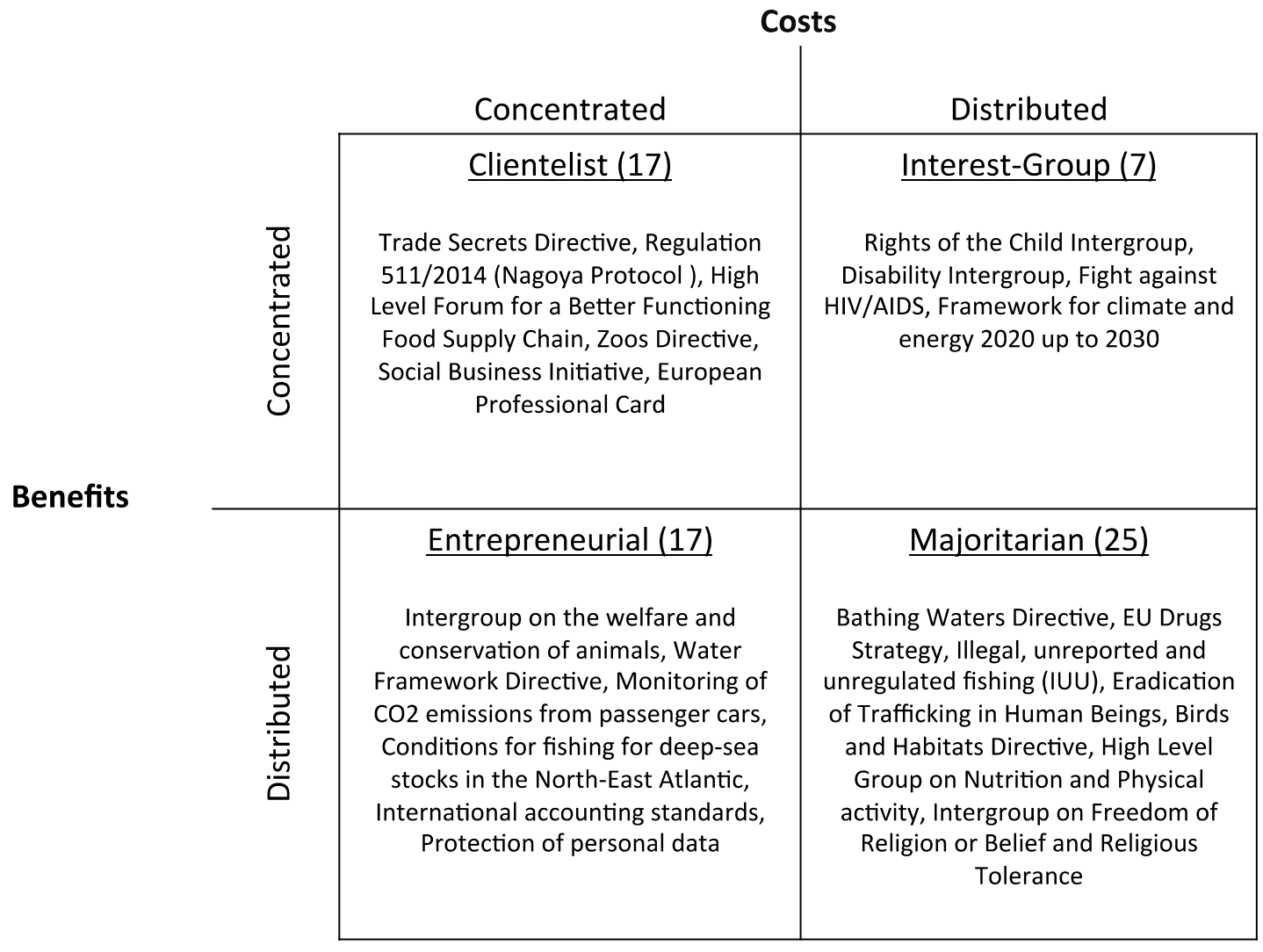

Source: Regulatory environments adapted from Wilson (1974, 1989), EU initiatives adapted from the EU Transparency Register (2017). 
The Fisher's exact test shows an association between policy type and policy environment variables: $x^{2}(n=66) p=.000$. Further observation of the distribution of policy types shows that the most prominent policy in clientelist environments is internal market, followed by health (Figure 3); in interest groups, it is freedom, then security and justice; in entrepreneurial environments, it is health followed by environment; and in majoritarian environments, it is environment. If the majoritarian environment conservation of marine biological resources is added to environment ( $44 \%$ and $12 \%$, respectively), the total percentage of environmental issues increases to $56 \%$. Moreover, four of the main policies in question move along vertical and horizontal axes (the dashed lines in Figure 3). The axes suggest that internal market and health policies are somewhat determined by certain threats to costs because they move along the clientelist and entrepreneurial axis. In parallel, freedom and security and justice move along the interest group and majoritarian axis, suggesting that distributed costs determine the environment. Finally, the organization of environmental policy along the entrepreneurial-majoritarian axis suggests that distributed benefits are an important determinant. 
Figure 3. Main EU policies followed by foundations, by regulatory environment (percentage of foundations), and key axes of distribution of some policies

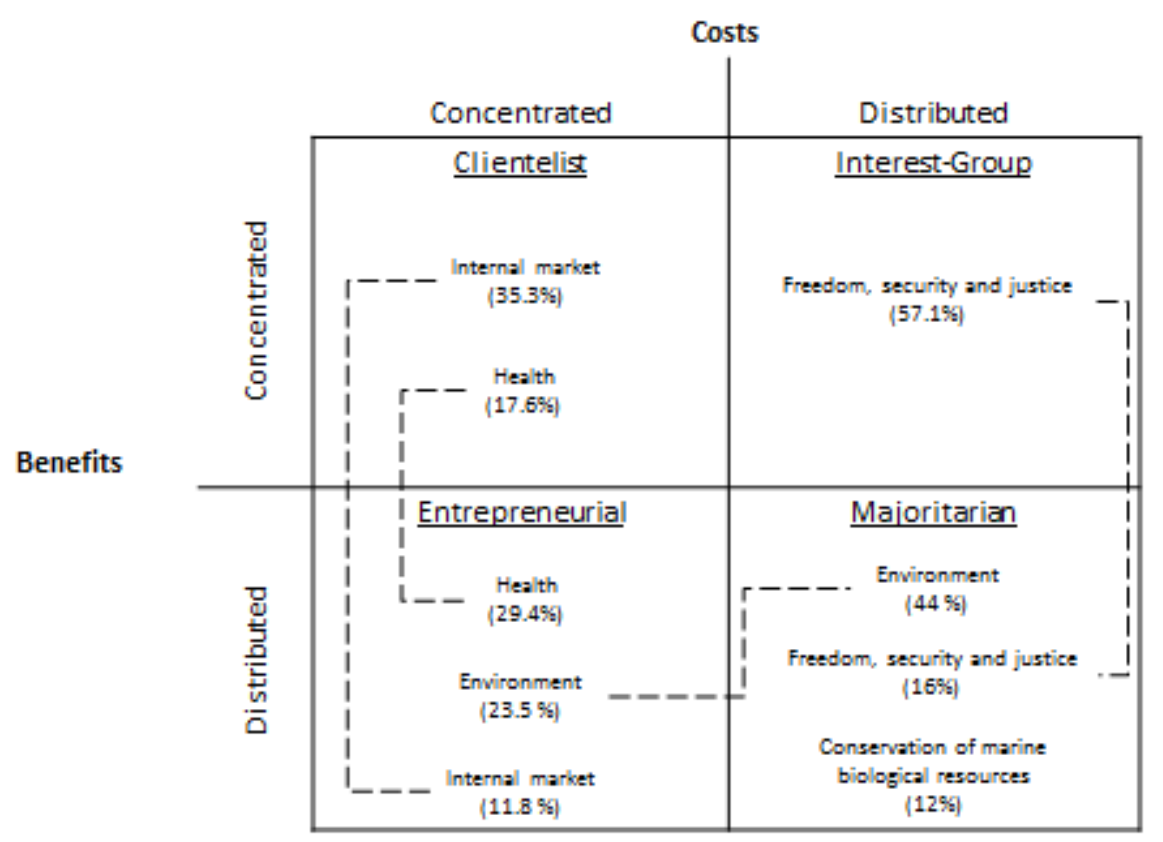

Source: Regulatory environments adapted from Wilson (1974, 1989), EU initiatives adapted from the EU Transparency Register (2017) 
The results of the Kruskal-Wallis test show that human resources (staff involved and FTE staff) are distinctively invested in majoritarian environments, while EP-accredited staff and financial resources (estimated costs and revenue) are similarly distributed across environments (Table 3). Further examination shows that the median number of staff involved and FTE staff in majoritarian environments more than doubles staff involved and FTE staff of each remaining environment ( $M d=5$ staff involved, 2.5 FTE staff). 
Table III. Kruskal-Wallis tests

Costs

(absolut

$\begin{array}{lcccc}\text { Persons } & & \text { EP } & e & \text { Costs } \\ \text { involved } & \text { FTE } & \text { accredited amount) } & \text { (range) Revenue }\end{array}$

\begin{tabular}{lcccccc}
\hline Chi-Square & 8.909 & 8.417 & 2.799 & 2.186 & 2.902 & .274 \\
$\boldsymbol{d f}$ & 3 & 3 & 3 & 3 & 3 & 3 \\
Asymp. Sig. & .031 & .038 & .424 & .535 & .407 & .965 \\
\hline
\end{tabular}

Source: Elaborated with data from the EU Transparency Register (2017). 


\section{Discussion}

The results show that foundations lobbying in the EU are somewhat distinct from the overall population of foundations in Europe in terms of distribution of resources and the countries they represent. This difference calls for more research, but it may have to do with subjects of interest (Graph 3), where only some foundations are attracted to the policy issues regulated at the EU level. Further research should consider whether these foundations tend to bypass national politics and engage directly in EU politics for the policy topics in question (e.g., Dür \& Mateo, 2012; Rodela, Udovč, \& Boström, 2016). Attitudes toward policymaking as a mode of organizing transactions may be another reason. For instance, while Belgian foundations tend to react passively to the idea of social change through policy engagement (Pirotte, 2007), Dutch foundations tend to respond actively (Gouwenberg, van der Jagt, \& Schuyt, 2007). These attitudes are related to Wilson's model — based on interest groups' perceptions of benefits and costs - ; therefore, they should be further studied via this model.

Contrary to the basic premises of the model, the results show that foundations significantly participate in majoritarian environments. Moreover, foundations' engagement in majoritarian environments is driven to some extent by their assessment of distributed benefits, while in clientelist and entrepreneurial environments, the main driver seems to be the costs. These results are in line with the argument that nonprofits, and foundations in particular, hold a distinctive position in this model compared to firms and unions, for example, as a result of their focus on the common good and particular capacity to represent highly fragmented interests (e.g., Anheier \& Daly, 2007; Anheier \& Leat, 2013; Prewitt, 2006). Moreover, these results are in line with the main argument posed in the introduction that foundations participate in EU policymaking for regulatory transactions that are too costly to solve inside the organization - in this case, highly fragmented interests that are difficult to define and mobilize. Nevertheless, the irregularity of foundation participation across regulatory 
environments requires further in-depth analysis on foundations' assessment of costs and benefits in their regulatory transactions.

The results suggest that lobby budgets (estimated costs) are similarly distributed across regulatory policy environments. This contradicts research on interest group access to policymaking, which found that lobbying budgets are more important for "special interest groups" (usually concentrated in clientelist and entrepreneurial environments) than for "diffuse interest groups" (usually concentrated in interest group and majoritarian environments) (Rasmussen \& Gross, 2015: 364). Nevertheless, Rasmussen and Gross (2015) studied interest groups globally. Consequently, my results add to those of Rasmussen and Gross, suggesting that for some types of interest groups, such as foundations, lobbying budgets do not vary across regulatory policies. Overall, the analysis suggests that applying a model that systematically orders policies and classifies interest groups may contribute to a more refined understanding of lobbying in the EU.

Finally, the results show that the density of human resources (i.e., staff involved and FTE staff) is greater in majoritarian environments than in the remaining regulatory environments. These results are difficult to analyze. It could be argued that the difficulties in identifying and understanding the implications for beneficiaries and cost bearers of majoritarian transactions impel EU institutions to seek a wide number of experts in these environments, as per the example of the ECNC in legislating IAS. Nevertheless, large numbers of staff does not imply that they provide idiosyncratic policy advice, nor does it imply that there is frequent or significant contact between the staff and EU politicians and other interest groups. The role of experts is one of the most challenging issues in interest group research (e.g., Chalmers, 2013; Gornitzka \& Sverdrup, 2008, 2011). Nevertheless, the results reflect the importance of 
foundations investing in staff in order to advance in majoritarian environments, a finding that requires further study.

This study has several limitations in addition to the weaknesses of the data in terms of exhaustiveness and sample size. The analysis concentrates on foundations and calls for comparative research that contrasts these with other nonprofit organizations and interest groups such as firms and consultants. A comparative approach would refine the model by explaining the cost-benefit assessment of different policy actors and their priorities in regulatory transactions. Furthermore, this analysis concentrates on costs (financial and staff investments) and overlooks the assessment of benefits, which seem to play an important role at least for foundations. Accordingly, because the identification of added value is a feature of hybrids (Ménard, 2010, 1013), further research should explore the cost-benefit logic that impels foundations to engage in public agency regulatory transactions.

\section{Conclusion}

Advancing our understanding of nonprofit cooperation requires using models and approaches suited for this purpose. This article proposed a transaction costs economic (TCE) approach to analyze a form of cooperation that is widely used in economics and organization studies: hybrids. Following the efficient alignment hypothesis, the TCE approach provides tools to model how nonprofits decide to pursue their transactions through hybrids and examine the organizational characteristics of different modes of hybrids. As a result, hybrids are a useful tool to further the comparative research on nonprofit cooperation.

I hypothesized that foundations cooperate in EU policymaking to conduct regulatory transactions that are too costly to solve individually. Accordingly, the results show that foundations lobby on regulatory environments, and significantly, on those of a majoritarian 
nature (where the beneficiaries and the cost bearers of a policy are highly fragmented and are difficult to mobilize as a group), such as the EU regulation on IAS. Among the regulatory environments examined, the majoritarian corresponds to the hybrid with the highest coordination costs. Moreover, the results suggest that foundations are driven into majoritarian environments by not only the costs, but also the benefits, of the transactions. Thus, as the TCE approach to hybrids suggests, the lobbying motivations for foundations are related to the added value that they perceive. This augments previous research on nonprofits (Almog-Bar, 2013; AL-Tabbaa, Leach, \& March, 2014), which found that added value is a key element driving nonprofit cooperation. Consequently, further research adopting the TCE approach to hybrids should improve the operationalization of the cost-benefit relation of nonprofit cooperation. Finally, this research contributes to TCE by shedding light on the specificities of the nonprofit logic of transaction costs, which according to the results, may differ from those of firms. 


\section{Notes}

${ }^{a}$ See https://www.irs.gov/charities-non-profits/private-foundations/lobbying-activity-ofsection-501-c-3-private-foundations

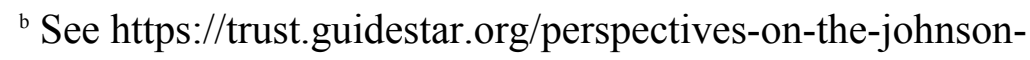

amendment?utm_campaign $=$ GuideStar + Newsletter +-

+ Researchers + and + Media\&utm_source $=$ hs_email\&utm_medium $=$ email\&utm_content $=4275$ 0102\&_hsenc $=$ p2ANqtz-

8342u549mLXOy33a4rzs8KLvT0g94wc8jr5ypfB6GkeLnZMuAfswXXWmBHRdfWxsCZro HmrJjr12lkxfUelAFyEClYLg\&_hsmi=42750102

${ }^{\mathrm{c}}$ See the list of participants here:

http://ec.europa.eu/transparency/regexpert/index.cfm?do=groupDetail.groupDetail\&groupID= 2210\&NewSearch $=1 \&$ NewSearch $=1$

d See, for example, collective action (Commons, 1950: 23), congress and environments (Wilson, 1989: 248).

${ }^{\mathrm{e}}$ Previously, each institution had separate registers (Greenwood \& Dreger, 2013; Greenwood, 2011).

${ }_{\mathrm{f}}^{\mathrm{f}}$ See http://ec.europa.eu/transparency/regexpert/index.cfm?do=faq.faq\&aide $=2$

${ }^{g}$ See http://eur-lex.europa.eu/legal-

content/EN/TXT/HTML/?uri=URISERV:ai0020\&from=EN 


\section{References}

Anheier, H. K., and Daly, S. (2007). Politics of Foundations: A Comparative Analysis, Routledge, Florence.

Anheier, H. K., and Leat, D. (2013). Philanthropic foundations: what rationales? Social Research: An International Quarterly, 80, 2, 449--472.

AL-Tabbaa, O., Leach, D., and March, J. (2014). Collaboration between nonprofit and business sectors: a framework to guide strategy development for nonprofit organizations. Voluntas, 25, 657--678.

Arrow, K. (1969). The organization of economic activity: issues pertinent to the choice of market versus nonmarket allocation. In U.S. Joint Economic Committee, 91st Congress, 1st Session, The Analysis and Evaluation of Public Expenditure: The PPB System, 2, 59-73, U.S. Government Printing Office, Washington D.C.

Ball, S. J. (2008). New philanthropy, new networks and new governance in education. Political Studies, 56, 747--765.

Ball, S. J. (2012). Global Education Inc.: New Policy Networks and the Neo-Liberal Imaginary, Routledge, Abingdon.

Battilana, J., and Lee, M. (2014). Advancing research on hybrid organizing - insights from the study of social enterprises. The Academy of Management Annals, 8, 1, 397--441.

Brandsen, T., de Donk, W., and Putters, K. (2005). Griffins or chameleons? Hybridity as a permanent and inevitable characteristic of the third sector. International Journal of Public Administration, 28, 9-10, 749--765.

Broscheid, A., and Coen, D. (2007). Lobbying activity and fora creation in the EU: empirically exploring the nature of the policy good. Journal of European Public Policy, $14,3,37--41$.

Chalmers, A. W. (2013). With a lot of help from their friends: explaining the social logic of informational lobbying in the European Union. European Union Politics, 14, 4, 475-- 
496.

Chalmers, A. W. (2014). Getting a seat at the table: capital, capture and expert groups in the European Union. West European Politics, 37, 5, 976--992.

Cheung, S. N. S. (1983). The contractual nature of the firm. The Journal of Law and Economics, 26, 1, 1--21.

Coase, R. (1937). The nature of the firm. Economica, 4, 16, 386--405.

Commons, J. (1950). The Economics of Collective Action, The Macmillan Company, New York.

Dür, A., and Mateo, G. (2012). Who lobbies the European Union? National interest groups in a multilevel polity. Journal of European Public Policy, 19, 7, 969--987.

EC. (2001). European governance: a white paper, COM, 2001, 428, Brussels.

EC. (2002). Towards a culture of consultation and dialogue - general principles and minimum standards for consultation of interested parties by the Commission, Communication From the President to the Commission, Brussels.

EC. (2010). Framework for commission expert groups: horizontal rules and public register, Communication from the President to the Commission, Brussels.

EC. (2015). Commission implementing decision of 30.6.2015, 30.6.2015 COM 2015, 4574 final, Brussels.

EP. (1999). Rules governing the establishment of intergroups, Brussels.

EP. (2015). Commission and Parliament implement new rules on transparency register, Press Release, Brussels, Retrieved from http://europa.eu/rapid/press-release_IP-153740_en.htm

EU Transparency Register. (2017). Retrieved from http://ec.europa.eu/transparencyregister/public/consultation/statistics.do?locale=en\&action=pr epareView

Ferris, J. (Ed.). (2009). Foundations and Public Policy. Leveraging Philanthropic Dollars, 
Knowledge, and Networks for Greater Impact, Foundation Center, New York.

Fondation de France, and CerPhi. (2015). An overview of philanthropy in Europe.

Observatoire de la Fondation de France/CerPhi, Bain \& Company, Paris.

Genovesi, P., and Shine, C. (2004). European strategy on invasive alien species. Nature and Environment, Council of Europe Publishing, 137.

Gornitzka, §., and Sverdrup, U. (2008). Who consults? The configuration of expert groups in the European Union. West European Politics, 31, 4, 725--750.

Gornitzka, Å., and Sverdrup, U. (2011). Access of experts: information and EU decisionmaking. West European Politics, 34, 1, 48--70.

Gouwenberg, B. M., van der Jagt, C. E., and Schuyt, T. (2007). Netherlands. In H. K. Anheier, and S. Daly (eds.), The Politics of Foundations. A Comparative Analysis, Routledge, New York, 239--255.

Greenwood, J. (2011). Interest Representation in the European Union (3rd. ed.), Palgrave Macmillan, Houndmills.

Greenwood, J., and Dreger, J. (2013). The transparency register: a European vanguard of strong lobby regulation? Interest Groups \& Advocacy, 2, 2, 139--162.

Greenwood, J., and Halpin, D. (2007). The European Commission and the public governance of interest groups in the European Union: seeking a niche between accreditation and laissez-faire. Perspectives on European Politics and Society, 8, 2, 189--210.

Guo, C., and Acar, M. (2005). Understanding collaboration among nonprofit organizations: combining resource dependency, institutional, and network perspectives. Nonprofit and Voluntary Sector Quarterly, 34, 3, 340--361.

Jäger, P. U., and Schroër, A. (2014). Integrated organizational identity: a definition of hybrid organizations and a research agenda. Voluntas, 25, 1281--1306.

James, K. (2016). More than rehabilitation: a conversation with a free-ranging wildlife veterinarian. DVM360 Magazine, Retrieved from 
http://veterinarynews.dvm360.com/more-rehabilitation-conversation-with-free-rangingwildlife-veterinarian

Jolink, A., and Niesten, E. (2012). Recent qualitative advances on hybrid organizations: taking stock, looking ahead. Scandinavian Journal of Management, 28, 149--161.

Kettunen, M., Genovesi, P., Gollasch, S., Pagad, S., Starfinger, U. ten Brink, P., and Shine, C. (2008). Technical support to EU strategy on invasive species (IAS) - assessment of the impacts of IAS in Europe and the EU (final module report for the European Commission). Institute for European Environmental Policy (IEEP), Brussels, Belgium.

Kretchmar, K., Sondel, B., and Ferrare J. J. (2014). Mapping the terrain: Teach For America, charter school reform, and corporate sponsorship. Journal of Education Policy, 9, 6, $742-$ $-759$.

Kumar, S., and Malegeant, P. (2006). Strategic alliance in a closed-loop supply chain: a case of manufacturer and eco-non-profit organization. Technovation, 26, 1127--1135.

Leat, D. (2016). Philanthropic foundations, public good and public policy, Palgrave Macmillan, London.

Lowery, D. (2007). Why do organized interests lobby? A multi-goal, multi-context theory of lobbying. Polity, 39, 1, 29--54.

Lowery, D., and Gray, V. (2004). A neopluralist perspective on research on organized interests. Political Research Quarterly, 57, 1, 163--175.

Mandeville, J. (2007). Public policy grant making: building organizational capacity among nonprofit grantees. Nonprofit and Voluntary Sector Quarterly, 36, 2, 282--298.

Ménard, C. (2004). The economics of hybrid organizations. Journal of Institutional and Theoretical Economics, 160, 3, 345--376.

Ménard, C. (2010). Hybrid organizations. In P. Klein, and M. Sykuta (eds.), The Elgar Companion to Transaction Costs Economics, Edward Elga, Cheltenham, 176--184.

Ménard, C. (2013). Hybrid modes of organization. Alliances, joint ventures, networks, and 
other strange animals. In R. Gibbons, and J. Roberts (eds.), The Handbook of Organizational Economics, Princeton University Press, Princeton, NJ, 1066--1105.

Moe, T. M. (1995). The politics of structural choice: toward a theory of public bureaucracy. In O. E. Williamson (ed.), Organization Theory. From Chester Barnard to the Present and Beyond, Oxford University Press, New York, 116--153.

Moe, T. M. (2007). Political institutions: the neglected side of the story. Journal of Law, Economics, and \& Organization, 6, 213--253.

Moe, T. M. (2011). Special Interest: Teachers Unions and America’s Public Schools. Washington, D.C.: The Brookings Institution.

Oster, S. (1992). Nonprofit organizations as franchise operations. Nonprofit Management and Leadership, 2, 3, 223--238.

Oster, S. (1996). Nonprofit organizations and their local affiliates: a study in organizational forms. Journal of Economic Behavior \& Organisation, 30, 83--95.

Ostrom, E. (1990). Governing the Commons: The Evolutions of Institutions for Collective Action, Cambridge University Press.

Ostrom, E. (2010). Analyzing collective action. Agricultural Economics, 41, 1, 155--166.

Pirotte, G. (2007). Belgium. In H. K. Anheier, and S. Daly (eds.), The Politics of Foundations. A Comparative Analysis, Routledge, New York, 85--95.

Prewitt, K. (2006). American foundations: what justifies their unique privileges and powers. In K. S. Prewitt, M. Dogan, S. Heydemann, and S. Toepler (eds.), The Legitimacy of Philanthropic Foundations: United States and European Perspectives, Russel Sage Foundation, New York, 27--46.

Rasmussen, A., and Gross, V. (2015). Biased access? Exploring selection to advisory committees. European Political Science Review, 7, 343--372.

Rodela, R., Udovč, A., and Boström, M. (2016). Developing environmental NGO power for domestic battles in a multilevel context: lessons from a Slovenian case. Environmental 
Policy and Governance.

Roelofs, J. (2003). Foundations and Public Policy. The Mask of Pluralism, State University of New York Press, NY.

Schiller, R. S., and Almog-Bar, M. (2013). Revisiting collaborations between nonprofits and businesses: a nonprofit-centric view and typology. Nonprofit and Voluntary Sector Quarterly, 42, 5, 942--962.

Stokes, K. E., O’Neill, K. P., Montgomery, W. I., Dick, J. T. A., Maggs, C. A., and McDonald, R. A. (2006). The importance of stakeholder engagement in invasive species management: a cross-jurisdictional perspective in Ireland. Biodiversity and Conservation, 15, 2829--2852.

Stone, D. (2010). Private philanthropy or policy transfer? The transnational norms of the open society institute. Policy \& Politics, 38, 2, 269--287.

U.S. Bureau of Labor Statistics. (2017). U.S. Department of Labor, Occupational Outlook Handbook, 2016-17 Edition, Zoologists and Wildlife Biologists. Retrieved from https://www.bls.gov/ooh/life-physical-and-social-science/zoologists-and-wildlifebiologists.htm

Valentinov, V. (2008a). The transaction cost theory of the nonprofit firm: beyond opportunism. Nonprofit and Voluntary Sector Quarterly, 37, 1, 5--18.

Valentinov, V. (2008b). Toward an incentive alignment theory of nonprofit organization. Evolutionary and Institutional Economics Review, 5, 1, 189--196.

Valentinov, V. (2009) Mapping the Third Sector in John R. Commons' Typology of Transactions, Journal of Economic Issues, 43, 4, 917--930.

Valentinov, V. 2012. The economics of the nonprofit sector: Insights from the institutionalism of John R. Commons. The Social Science Journal, 49, 545--553.

Williamson, O. E. (1979). Transaction-cost economics: the governance of contractual relations. The Journal of Law and Economics, 22, 2, 233--261. 
Williamson, O. E. (1985). The Economic Institutions of Capitalism, Free Press, New York, NY.

Williamson, O. E. (1991). Comparative economic organization: the analysis of discrete structural alternatives. Administrative Science Quarterly, 36, 2, 269--296.

Williamson, O. E. (1996). The Mechanisms of Governance, Oxford University Press, Oxford.

Williamson, O. E. (1999). Public and private bureaucracies: a transaction cost economics perspective. Journal of Law, Economics, \& Organization, 15, 306--342.

Williamson, O. E., Watcher, M. L., and Harris, J. (1975). Understanding the employment relation: the analysis of idiosyncratic exchange. The Bell Journal of Economics, 6, 1, $250--278$.

Wilson, J. Q. (1974). The politics of regulation. In J. McKie (ed.), Social Responsibility and the Business Predicament, Brookings Institution, Washington, 135--168.

Wilson, J. Q. (1989). Bureaucracy. What Government Agencies Do and Why They Do It, Basic Books, New York, NY.

Witesman, E., and Heiss, A. (2016). Nonprofit collaboration and the resurrection of market failure: how a resource-sharing environment can suppress social objectives. Voluntas.

Young, D. (1989). Autonomy in a franchise age: structural change in national voluntary associations. Nonprofit and Voluntary Sector Quarterly, 18, 2, 101--117.

Young, D., and Faulk, L. (2010). Franchises and federations: the economics of multi-site nonprofit organizations. In B. Seaman, and D. Young (eds.), Handbook of Research on Nonprofit Economics and Management, Edward Elgar, Cheltenham, 220--237. 